\title{
Thermoregulation of paraplegic and able bodied men during prolonged exercise in hot and cool climates
}

\author{
B Dawson PhD, J Bridle MSc, R J Lockwood PhD
}

Exercise Physiology Laboratory, Department of Human Movement, University of Western Australia, Nedlands, 6009 Australia.

\begin{abstract}
The purpose of this study was to compare the thermoregulatory responses of trained paraplegics (TP) and able bodied subjects (AB) performing submaximal exercise of the same relative intensity in both hot and cool conditions. Five TP (lesion range $\mathrm{T} 12$ to $\mathrm{L} 3$ ) and five $\mathrm{AB}$ subjects experienced in wheelchair use performed 60 minutes of constant load $\left(55-60 \%\right.$ of $\left.\dot{\mathrm{VO}}_{2} \max \right)$ arm ergometry exercise in $37^{\circ} \mathrm{C}$ and $15^{\circ} \mathrm{C}$ climatic conditions. Heart rate (HR), sweat rate and rectal (Tr) and skin (Tsk) temperatures were recorded. In the hot climate the TP subjects recorded a significantly greater change in $\bar{T}$ sk $(\Delta \overline{\mathrm{T}} \mathrm{sk})$ from 0 to 60 minutes of exercise than the $\mathrm{AB}$ subjects, because of greater thigh and calf temperatures, but no other significant differences were found between these groups. In the cool climate no significant differences were observed between the $\mathrm{TP}$ and $\mathrm{AB}$ groups. It was concluded that $\mathrm{TP}$ have a similar thermoregulatory ability to $\mathrm{AB}$ subjects who perform identical prolonged exercise in hot and cool conditions, although their lower limb skin temperatures are greater, probably because of venous pooling in the legs. While these results are a promising indication of the ability of TP to thermoregulate effectively while exercising in the, heat caution regarding their participation in endurance competitions in hot conditions should be expressed until data collected during wheelchair exercise (rather than arm ergometry) in the heat is available.
\end{abstract}

Keywords: sweat rate; rectal and skin temperature; spinally injured; maximal oxygen consumption; arm cranking.

\section{Introduction}

Sport and exercise programmes are now assuming a larger role in the rehabilitation of the spinally injured, which has resulted in an increased participation in events traditionally reserved for the able bodied. Many of these sporting activities involve prolonged (60 min or more) exercise at intensities requiring greater than $50 \%$ of maximal oxygen consumption $\left(\dot{\mathrm{VO}}_{2} \max \right)$. The varied environmental conditions under which these activities are conducted also warrant consideration from the viewpoint of safety. For example, marathons require prolonged exercise at a high intensity of effort (greater than $70 \% \dot{\mathrm{VO}}{ }_{2}$ max.), ${ }^{1}$ and often must be performed in hot and/or humid conditions which places severe demands on the cardiovascular and thermoregulatory systems of the body.

When paraplegics expose themselves to such physiological strain and environmental stress, they may experience great difficulty in regulating their body temperature within safe limits. According to Seckendorf and Randall, ${ }^{2}$ spinally injured persons have an impaired centrally-driven sweating response, with the extent of this impairment being related to the level of spinal lesion, and to the lowermost intact sympathetic connections. Despite the presence of local temperature reflexes originating in the skin, the spinal cord and from intra-abdominal receptors, ${ }^{3}$ the extent to which the centrally driven sweating response is inhibited by the spinal lesion will ultimately have a marked 
influence on body temperature regulation during prolonged exercise. Therefore, although spinal reflex sweating ${ }^{4}$ is present in the paraplegic below the level of the spinal lesion, it alone may not be powerful enough to regulate body temperatures within safe limits during prolonged exercise.

When paraplegics exercise in a hot environment, their reduced central sweating response may result in thermoregulatory strain which is not present in able bodied persons performing at the same exercise intensity in identical environmental conditions. In addition to a limited central sweating response, paraplegics will also have a reduced convective heat exchange as a result of their normal practice of competing in tracksuit pants. Whether paraplegics can regulate their body temperature at the same level as able bodied subjects performing identical exercise in the same environmental conditions has not been widely investigated. Only Fitzgerald et al, ${ }^{5}$ who found paraplegic women experienced greater thermoregulatory strain than able bodied women when performing wheelchair ergometry in cool conditions have reported data on this topic.

Also, although the effects of acute and prolonged wheelchair exercise in cool environmental conditions have been investigated elsewhere, ${ }^{6-9}$ the thermoregulatory responses of paraplegics performing prolonged physical exercise in hot conditions has not been studied. Therefore, it was the purpose of this study to investigate these questions by comparing the thermoregulatory responses of paraplegic and able bodied subjects to prolonged submaximal exercise in both hot and cool conditions.

\section{Methods and procedures}

\section{Sample}

Five trained male paraplegics (TP) and five able bodied (AB) males participated as subjects in the study. Their characteristics are presented in Table I. The paraplegic subjects were cleared to participate in the study by a medical registrar from the Royal Perth (Rehabilitation) Hospital. The TP were all members of a wheelchair basketball team, with three of them currently playing

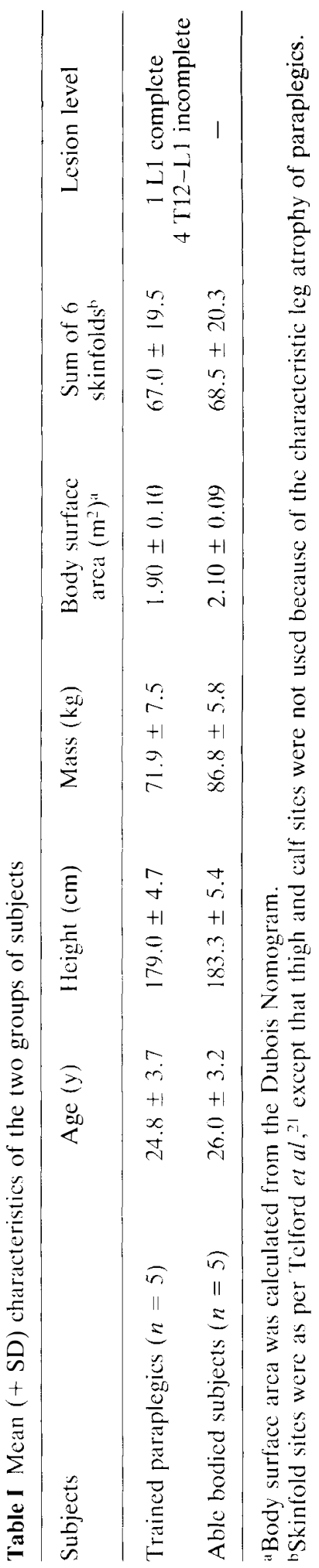


for the Western Australian state wheelchair basketball team. All subjects had been training at least one night per week and playing at least one game of basketball per week for the past 3 months. Two of the subjects were also actively involved in training for disabled athletic events. Trained paraplegics were sought as subjects for this study as they are likely to possess better exercise-heat tolerance than untrained paraplegics, as is the case with trained and untrained able bodied persons. ${ }^{10,11.12}$

The AB subjects were members of a wheelchair basketball team and had been playing for a minimum of two seasons, thus were deemed to be 'experienced' wheelchair users. These persons were selected as subjects because they were accustomed to exercise utilising the upper body musculature, hence allowing for a better comparison of data between groups.

All subjects were fully informed of the experimental procedures and all gave their informed consent prior to performing any testing. The study was approved by the Human Rights Committee of the University of Western Australia.

\section{Experimental design}

The study consisted of three separate experimental stages; (1) maximal physiological profiling of each subject; (2) $60 \mathrm{~min}$ of constant load arm cranking at approximately $55-60 \%$ of each subject's $\dot{\mathrm{VO}}_{2}$ max. (as determined from stage 1) in a hot, dry $\left(37.4 \pm 0.3{ }^{\circ} \mathrm{C} \quad \mathrm{T}_{\mathrm{DB}} ; \quad 24.4 \pm 0.3{ }^{\circ} \mathrm{C} \quad \mathrm{T}_{\mathrm{WB}}\right.$; $33.0 \pm 1.9 \% \mathrm{RH})$ climate; and (3) an identical protocol as for stage 2, except that subjects exercised in a cool $\left(15.0 \pm 0.2^{\circ} \mathrm{C}\right.$ $\left.\mathrm{T}_{\mathrm{DB}} ; 10.5 \pm 0.2^{\circ} \mathrm{C} \mathrm{T}_{\mathrm{WB}} ; 56.9 \pm 2.1 \% \mathrm{RH}\right)$ climate.

On average, each subject had a 7 day break between each stage. During stages 2 and 3 the tests and treatments for each subject were conducted at the same time of the day $( \pm 1 \mathrm{~h})$ to minimise variation due to the circadian rhythm of body temperature. ${ }^{13}$

\section{Preliminary testing (stage 1)}

A maximal arm crank test to volitional exhaustion was conducted on a Seimens-
Elema 380B electromagnetically braked arm crank ergometer and performed in a controlled laboratory environment $\left(21^{\circ} \mathrm{C}\right.$, $50 \% \mathrm{RH})$. Each subject cranked in a seated upright position with the seat height standardised so that the crank shaft was $15 \mathrm{~cm}$ above the heart. ${ }^{14}$ The placement of the seat, as recommended by Williams et $a l,{ }^{15}$ was such that it allowed a slight flexion at the elbow at the point of maximal pedal excursion. Also, straps were placed around each subject's thigh and ankles, and the seat height was such that the feet could not touch the floor. This was done to prevent the able bodied subjects from using their lower body musculature to achieve a more stable position while cranking.

The arm crank ergometer was set in constant power mode and the subject was instructed to crank at 70 revolutions per min (rpm). A comfortable workload $\left(200 \mathrm{kpm} \mathrm{min}^{-1}\right)$ was selected for the first $3 \mathrm{~min}$. At the end of the initial $3 \mathrm{~min}$ the workload was increased to $300 \mathrm{kpm} \mathrm{min}^{-1}$. From this point on the workload was increased by $50 \mathrm{kpm} \mathrm{min}^{-1}$ every 2 min until volitional exhaustion.

Inspired volume $\left(\dot{\mathrm{V}}_{1}\right)$ was recorded by a Morgan Ventilometer Mark 2. The expired gas was simultaneously analysed for its oxygen $\left(\mathrm{F}_{\mathrm{E}} \mathrm{O}_{2}\right)$ and carbon dioxide $\left(\mathrm{F}_{\mathrm{E}} \mathrm{CO}_{2}\right)$ content with an Applied Electrochemistry S-3A oxygen analyser and Datex CD-101 carbon dioxide analyser. The $\mathrm{F}_{\mathrm{E}} \mathrm{O} 2, \mathrm{~F}_{\mathrm{E}} \mathrm{CO}_{2}$, $\dot{\mathrm{V}}_{1 \text { (ATPS) }}$ and $\dot{\mathrm{VO}}_{2 \text { (STPD) }}$ were recorded every $30 \mathrm{~s}$. Heart rate (HR) was recorded in the last $10 \mathrm{~s}$ of each minute of the test, and in the final $10 \mathrm{~s}$ of exercise using a Siemens Cardiostat 701 electrocardiograph (ECG). Before each test the gas analysers were calibrated with gases of known concentrations (gravimetrically determined) and the Morgan Ventilometer was calibrated by drawing a known volume of air through it using a 1 litre syringe.

Blood lactate concentrations [Hla] were obtained from $25 \mu \mathrm{l}$ capillary blood samples taken from the earlobe at 1, 3, 5 and $7 \mathrm{~min}$ post exercise, then analysed by an enzymatic oxidase method using an Analox LM3 multichannel analyser. Only the peak [Hla] value was recorded. A range of lactate standards $1 \mathrm{mmoll}^{-1}$ to $15 \mathrm{mmoll}^{-1}$ were 
routinely used to check the calibration of this analyser (mean coefficient of variation $1.5 \%)$.

\section{Controlled climate testing (stages 2 and 3)}

The workload intensity for the prolonged exercise tests in controlled climates (hot and cool) was set at a constant load equal to approximately $55-60 \%$ of each subject's $\mathrm{VO}_{2}$ max as determined from the maximum exercise test. The procedures, equipment and recording instruments used during the climate chamber test were identical for all subjects and for both tests. The only variation was in the environmental conditions existing in the chamber. The first prolonged exercise test was performed in the hot climate, and the second performed in the cool climate.

The subjects were stopped during any of these sessions if their rectal temperature (Tr) exceeded $39.5^{\circ} \mathrm{C}$, max HR was achieved, or they expressd a desire to cease because of exhaustion or discomfort. One paraplegic subject was unable to complete $60 \mathrm{~min}$ of exercise in the hot climate. This subject reached his max HR after 35 min and was immediately removed from the chamber. All subjects were able to successfully complete $60 \mathrm{~min}$ of exercise in the cool climate.

The subjects were prepared for the exercise tests in an air-conditioned laboratory with an ambient temperature of approximately $21^{\circ} \mathrm{C}$. On arrival at the climate chamber subjects drank $400 \mathrm{ml}$ of distilled water in an attempt to standardise the initial level of hydration. Nude body mass $( \pm 10 \mathrm{~g})$ (Avery 3350 AAE beam balance) was taken, then the leads for the recording of $\mathrm{Tr}$ (YSI model 401, inserted $10 \mathrm{~cm}$ beyond the anal sphincter), mean skin temperature (Tsk) (YSI model 408/409B) and HR (ECG) were attached. A YSI Model 46 TUC Telethermometer was used for temperature measurements and the weighted equation of Ramanathan ${ }^{16}$ was used for calculating $\overline{\mathrm{T}} \mathrm{sk}$.

Three min prior to entering the chamber a $25 \mu$ sample of blood was taken from the earlobe to measure pre-exercise [Hla]. The method of collection was the same as described previously. The subjects then entered the climate chamber and were seated at the arm crank ergometer and strapped into position as in stage 1 . Moving air $\left(0.03 \mathrm{~m} \mathrm{~s}^{-1}\right)$ was directed at their faces during the tests.

Five minutes after entering the climate chamber the subjects began cranking at $70 \mathrm{rpm}$ against a constant workload intensity set at approximately $55-60 \%$ of their $\dot{\mathrm{VO}}_{2}$ max using a Seimens-Elema 380B electromagnetically braked arm crank ergometer set in constant power mode as for the maximal capacity test. They cranked continuously for $60 \mathrm{~min}$, throughout which HR, $\overline{\mathrm{T}} \mathrm{sk}$, and $\operatorname{Tr}$ were measured every $5 \mathrm{~min}$; [Hla] during the 30th min and 1 min post exercise; $\dot{\mathrm{VO}}_{2}$ during the 19th, 39th and 59 th $\mathrm{min}$; and body mass $5 \mathrm{~min}$ post exercise (after removal of all leads and being towelled dry). The change in body mass (pre- to post-) was used to calculate sweat rate $\left(\mathrm{g} \mathrm{h}^{-1}\right)$. No corrections were made for respiratory water loss or metabolic weight loss. In these tests $\dot{\mathrm{V}}_{2}$ was measured by collecting expired air for $1 \mathrm{~min}$ in a 120 litre chain compensated Tissot Tank. A sample of expired air was withdrawn from the gasometer using a 2 litre rubber gas bag and analysed for $\mathrm{F}_{\mathrm{E}} \mathrm{CO}_{2}$ by a Datex Normocap carbon dioxide analyser and for $\mathrm{F}_{\mathrm{E}} \mathrm{O}_{2}$ by a Beckman OM-11 oxygen analyser.

\section{Treatment and analysis of the data}

An independent $t$-test and a two-way ANOVA with repeated measures were used to determine the significance of any differences observed between groups on the maximal arm cranking test and for the thermoregulatory data recorded during the controlled climate tests. When appropriate, post-hoc analysis (Fisher's PLSD) was used. Polynomial contrasts were also employed to test the significance of differences between goups in $\mathrm{Tr}, \overline{\mathrm{T}} \mathrm{sk}, \dot{\mathrm{VO}}_{2}$ and $\mathrm{HR}$ responses over time in each climate. The statistical package used made data adjustments for the paraplegic subject who failed to complete $60 \mathrm{~min}$ of exercise in the hot climate. A significance level of $p<0.05$ was set for all statistical decisions. 


\section{Results}

\section{A. Physiological responses to maximal exercise}

Table II presents the mean $( \pm S E)$ values for all variables measured during the performance of the maximal exercise capacity test for the two groups. The only significant difference $(p<0.01)$ found between the TP and $\mathrm{AB}$ subjects was for absolute $\mathrm{VO}_{2}$ max $\left(1 \mathrm{~min}^{-1}\right)$, with a greater value being recorded for the $\mathrm{AB}$ subjects. However, when $\dot{\mathrm{VO}}_{2}$ was expressed in relative $\left(\mathrm{ml} \mathrm{kg}^{-1} \mathrm{~min}^{-1}\right)$ terms, there was no significant difference between these two groups as the $\mathrm{AB}$ subjects on average were approximately $15 \mathrm{~kg}$ heavier than the TP. Maximum work time (WT) $(\mathrm{min})$ and max workload (WL) $\left(\mathrm{kpm} \mathrm{min}^{-1}\right)$ were very similar between TP and $\mathrm{AB}$ subjects.

\section{B. Physiological responses to prolonged exercise in controlled climates \\ (a) Oxygen consumption}

With duration of effort (19-59 min) both groups showed a significant $(p<0.01)$ increase in $\dot{\mathrm{V}} \mathrm{O}_{2}$ in the hot climate (TP: range 59 to $64 \% \dot{\mathrm{VO}}_{2}$ max and $\mathrm{AB}$ subjects: 56 to $64 \% \dot{\mathrm{VO}}_{2}$ max.), however, no significant increases in $\dot{\mathrm{VO}} 2$ in the cool climate were evident (TP: range 57 to $60 \% \dot{\mathrm{VO}}_{2}$ max and AB subjects: 52 to $57 \% \dot{\mathrm{VO}}_{2}$ max). When between group comparisions were made there were no significant differences recorded in $\mathrm{VO}_{2}$ in either climate.

\section{(b) Rectal temperature (Figure 1 shows} these values)

As would be expected, both groups recorded a significant increase in $\operatorname{Tr}$ $(p<0.01)$ across the exercise period in the hot climate. Between group comparisons showed that there were no significant differences in $\mathrm{Tr}$ response in the $\mathrm{TP}$ and $\mathrm{AB}$ subjects. The $\Delta \operatorname{Tr}$ values for $0-60 \mathrm{~min}$ were $0.65 \pm 0.12{ }^{\circ} \mathrm{C}$ in the TP and $0.70 \pm 0.15{ }^{\circ} \mathrm{C}$ (NS) in the AB subjects.

In the cool climate both groups recorded significant linear and quadratic changes in $\mathrm{Tr}$, exhibiting a plateau in $\operatorname{Tr}$ response, which indicated that they were able to achieve a steady state in core temperature. Between group comparsions showed there to be no significant differences in $\operatorname{Tr}$ response between the TP and AB subjects in the cool climate. The respective $\Delta \operatorname{Tr}$ values for $0-60 \mathrm{~min}$ (TP: $0.45 \pm 0.10^{\circ} \mathrm{C}$ and $\mathrm{AB}$ : $0.35 \pm 0.04^{\circ} \mathrm{C}$ ) also showed no significant between-group differences.

(c) Mean skin temperature (Figure 2 shows these values)

The AB subjects exhibited a steady decline in $\bar{T}$ sk in the last $30 \mathrm{~min}$ of the exercise period in the hot climate in contrast to the TP who recorded a steady rise in $\overline{\mathrm{T}} \mathrm{sk}$

Table II Physiological responses of the trained paraplegics and able bodied subjects to maximal arm cranking exercise

\begin{tabular}{|c|c|c|}
\hline Variable & Trained paraplegics & Able bodied subjects \\
\hline $\begin{array}{l}\dot{\mathrm{V}} \mathrm{O}_{2} \max \\
\left(1 \min ^{-1}\right)\end{array}$ & $\begin{array}{l}2.41 \pm 0.06 \\
(2.23-2.53)\end{array}$ & $\begin{array}{c}2.83 \pm 0.11^{* *} \\
(2.43-3.05)\end{array}$ \\
\hline $\begin{array}{l}\dot{\mathrm{V}} \mathrm{O}_{2} \max \\
\left(\mathrm{ml} \mathrm{kg}^{-1} \min ^{-1}\right)\end{array}$ & $\begin{array}{c}33.7 \pm 1.7 \\
(21.6-38.4)\end{array}$ & $\begin{array}{l}32.6 \pm 1.1 \\
(30.3-36.5)\end{array}$ \\
\hline $\begin{array}{l}\text { Max WL } \\
\left(\mathrm{kpm} \min ^{-1}\right)\end{array}$ & $\begin{array}{c}600 \pm 27 \\
(500-650)\end{array}$ & $\begin{array}{c}610 \pm 37 \\
(500-700)\end{array}$ \\
\hline $\begin{array}{l}\text { Max WT } \\
(\min )\end{array}$ & $\begin{array}{c}16.2 \pm 1.0 \\
(12.5-18.0)\end{array}$ & $\begin{array}{c}16.9 \pm 1.4 \\
(12.5-19.5)\end{array}$ \\
\hline $\begin{array}{l}\text { Max HR } \\
\text { (bpm) }\end{array}$ & $\begin{array}{l}188 \pm 4 \\
(173-197)\end{array}$ & $\begin{array}{l}185 \pm 6 \\
(165-200)\end{array}$ \\
\hline $\begin{array}{l}\text { Peak [Hla] } \\
\left(\mathrm{mMol} 1^{-1}\right)\end{array}$ & $\begin{array}{c}11.4 \pm 0.7 \\
(9.4-12.8)\end{array}$ & $\begin{array}{l}11.6 \pm 0.5 \\
(10.5-13.1)\end{array}$ \\
\hline
\end{tabular}

** $p<0.01$.

Values presented are $\bar{X} \pm$ SEM and the range of values. 

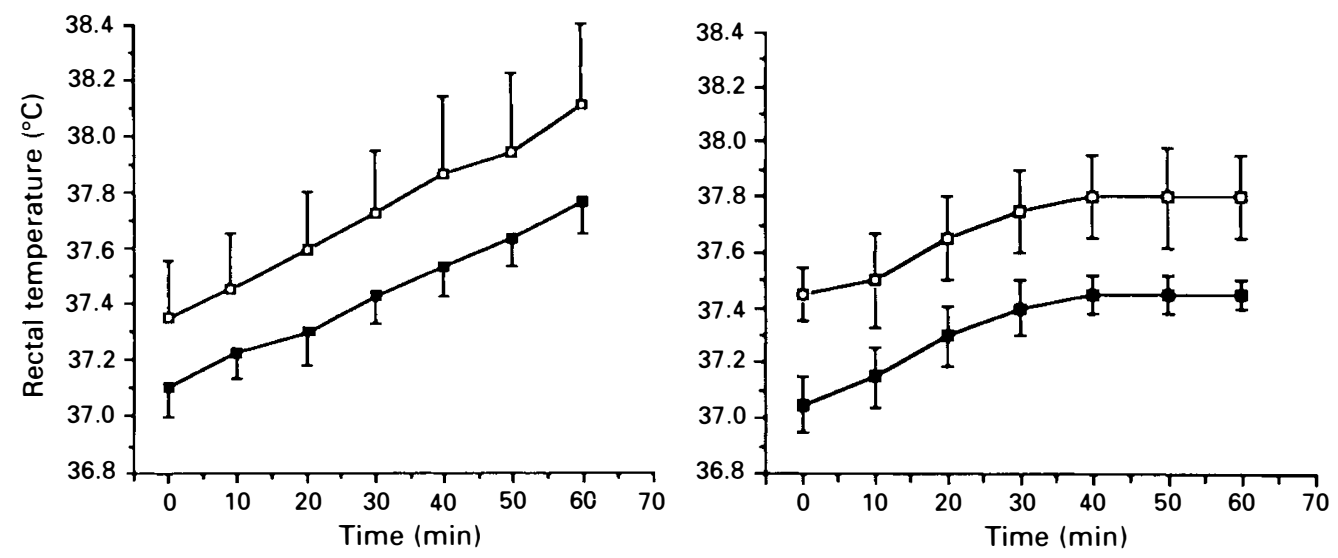

Figure 1 Mean $( \pm S E)$ rectal temperature responses of trained paraplegics (TP: - -) and able bodied (AB: $-\square-$ ) subjects during submaximal exercise in hot (left panel) and cool (right panel) climates.

Note: Hot climate: Both groups showed a significant linear $(p<0.01)$ increase over the exercise period. There was no significant interaction between TP and AB subjects.

Cool climate: Both groups showed a significant $(p<0.01)$ linear and quadratic change over the exercise period. There were no significant interactions between the TP and AB subjects.
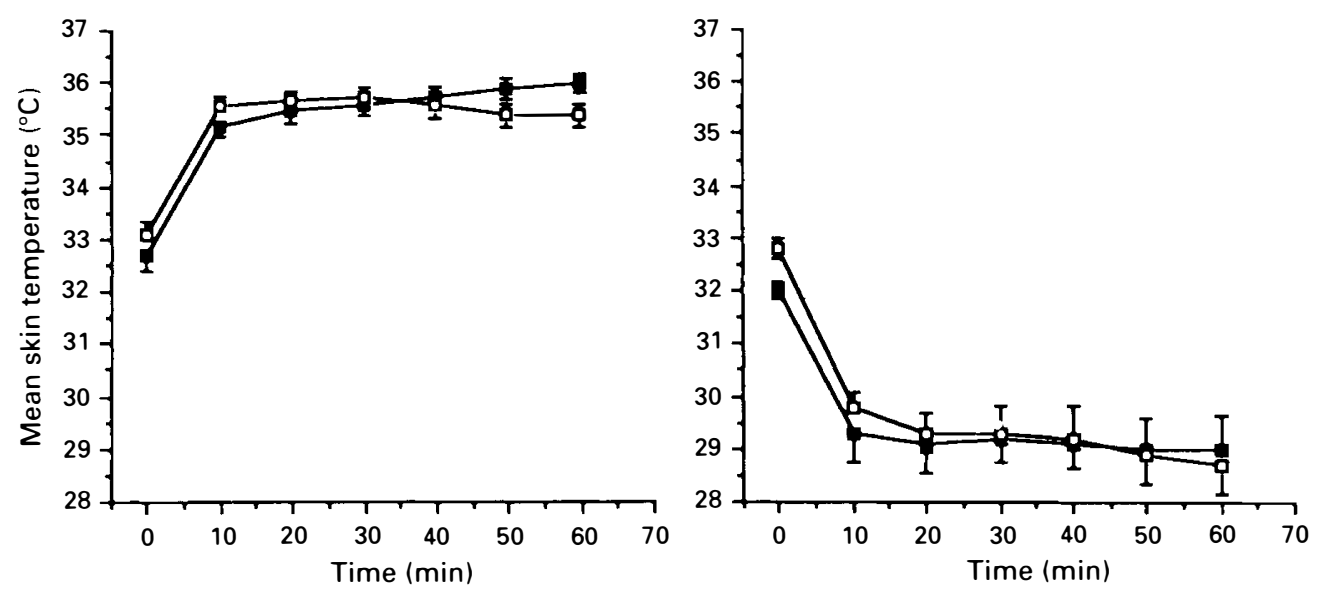

Figure 2 Mean $( \pm \mathrm{SE})$ skin temperature responses of trained paraplegics (TP: - ) and able bodied (AB: $\square-$ ) subjects during submaximal exercise in hot (left panel) and cool (right panel) climates.

Note: Hot climate: TP and AB subjects recorded a significant linear $(p<0.01)$ and quadratic $(p<0.05)$ change over the exercise period. A significant linear $(p<0.01)$ interaction was also recorded.

Cool climate: Both groups recorded a significant linear $(p<0.01)$ decrease over the exercise period. There were no significant interactions between the TP and AB subjects.

throughout. This resulted in a significant $(p<0.01)$ linear interaction between the two groups. The $\Delta \bar{T}$ sk values for $0-60 \mathrm{~min}$ support this finding as the $\mathrm{AB}$ subjects recorded a value of $2.25 \pm 0.32^{\circ} \mathrm{C}$, which was significantly lower $(p<0.05)$ than the $\mathrm{TP}\left(3.55 \pm 0.23^{\circ} \mathrm{C}\right)$.

In the cool climate both groups recorded 
a significant decrease $(p<0.01)$ in $\overline{\mathrm{T}} \mathrm{sk}$ across the exercise period. However, the between group comparisons showed that there were no significant interactions present. The $\Delta \overline{\mathrm{T}} \mathrm{sk}$ values $0-60 \mathrm{~min}$ also showed no significant differences (TP: $3.10 \pm 0.38^{\circ} \mathrm{C}$ and $\mathrm{AB}: 4.10 \pm 0.51{ }^{\circ} \mathrm{C}$ ) between groups.

\section{(d) Heart rate (Figure 3 shows these} results)

Heart rates were approximately $80-90 \%$ $\max \mathrm{HR}$ in the hot climate and approximately $65-70 \%$ max HR in the cool climate. A steady increase in HR across the exercise period was evident in each group in both climates (cardiovascular drift), with the exception of the $\mathrm{AB}$ subjects in the cool climate, who recorded a slight decrease in $\mathrm{HR}$ in the last $10 \mathrm{~min}$ of exercise. Between group comparisons showed there to be no significant differences in $\mathrm{HR}$ response between the TP and $\mathrm{AB}$ subjects in either climate.

(e) Blood lactic acid concentration (Table III shows these values)

In both climates the two groups recorded their highest [Hla] values after $30 \mathrm{~min}$ of exercise, with the subsequent $60 \mathrm{~min}$ values being slightly less. Between group comparisons showed there to be no significant differences in [Hla] values between the TP and the $\mathrm{AB}$ subjects in either climate.

(f) Sweat rate (These results are shown in Table III)

The $A B$ subjects recorded slightly greater sweat rates in both climates than the TP, but their respective values were not significantly different in either climate.

\section{Discussion}

\section{Fitness}

The $\dot{\mathrm{V}} \mathrm{O}_{2}$ max values measured here in the TP are very similar to those reported by Davis and Shephard ${ }^{17}$ who also tested paraplegic subjects. The TP and AB subjects' $\mathrm{VO}_{2}$ max values are higher than those reported by Van Loan et al, ${ }^{18}$ although their subject groups are likely to have included a wide range of fitness levels. In contrast, the TP $\dot{\mathrm{VO}}_{2}$ max values are lower than those reported by Gass et $a l^{9}$ for similarly well trained paraplegics. However, their subjects were tested in wheelchairs on a motor driven treadmill and generally this mode of exercise produces greater $\dot{\mathrm{V}} \mathrm{O}_{2}$ max values than arm crank ergometry. ${ }^{7}$ The TP and AB

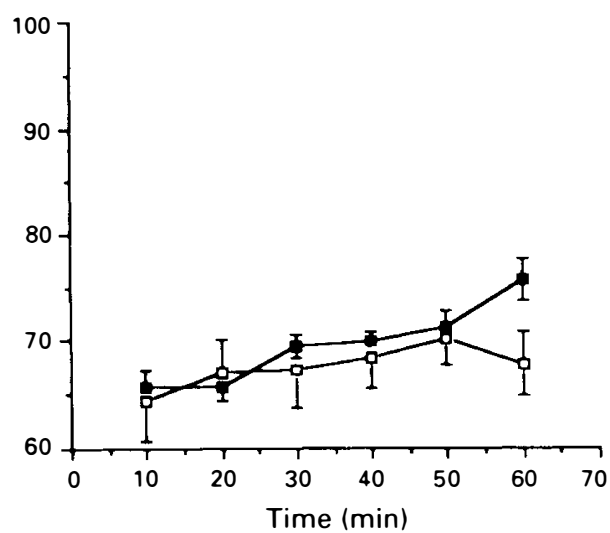

Figure 3 Mean $( \pm$ SE) heart rate responses of trained paraplegics (TP: -- ) and able bodied (AB: $-\square)$ subjects during submaximal exercise in hot (left panel) and cool (right panel) climates.

Note: Hot climate: Both groups recorded a significant linear $(p<0.01)$ and quadratic $(p<0.01)$ change over the exercise period. There were no significant interactions between the TP and $\mathrm{AB}$ subjects.

Cool climate: Both groups recorded a significant linear $(p<0.01)$ increase over the exercise period. There were no significant interactions between the TP and AB subjects. 
Table III Blood lactate concentrations [Hla] and sweat rates recorded for trained paraplegics and able bodied subjects during submaximal arm crank ergometer exercise in hot and cool climates

\begin{tabular}{|c|c|c|c|}
\hline & & Trained paraplegics & Able bodied subjects \\
\hline $\begin{array}{l}{[\mathrm{Hla}] \mathrm{mmol} 1^{-1}} \\
\text { Pre-Ex }\end{array}$ & $\begin{array}{l}\text { Hot } \\
\text { Cool }\end{array}$ & $\begin{array}{l}1.1 \pm 0.2 \\
1.0 \pm 0.1\end{array}$ & $\begin{array}{l}0.8 \pm 0.1 \\
0.8 \pm 0.1\end{array}$ \\
\hline 30 mins & $\begin{array}{l}\text { Hot } \\
\text { Cool }\end{array}$ & $\begin{array}{l}3.6 \pm 0.5 \\
2.7 \pm 0.3\end{array}$ & $\begin{array}{l}4.1 \pm 0.7 \\
3.3 \pm 0.6\end{array}$ \\
\hline $60 \mathrm{~min}$ & $\begin{array}{l}\text { Hot } \\
\text { Cool }\end{array}$ & $\begin{array}{l}2.9 \pm 0.5 \\
1.8 \pm 0.3\end{array}$ & $\begin{array}{l}3.4 \pm 0.5 \\
1.9 \pm 0.3\end{array}$ \\
\hline Sweat rate $\mathrm{gh}^{-1}$ & $\begin{array}{l}\text { Hot } \\
\text { Cool }\end{array}$ & $\begin{array}{l}962 \pm 17 \\
305 \pm 36\end{array}$ & $\begin{array}{c}1156 \pm 113 \\
396 \pm 59\end{array}$ \\
\hline
\end{tabular}

There were no significant differences between groups.

Values presented are $\bar{X} \pm$ SEM.

subjects were similar in all physiological measures except $\dot{\mathrm{V}} \mathrm{O}_{2} \max \left(1 \mathrm{~min}^{-1}\right)$. However, this difference was controlled for by having the subjects exercise at the same relative intensity (i.e. $55-60 \% \dot{\mathrm{V}}_{2} \max$ ) during the prolonged submaximal exercise tests. The level of core temperature reached during exercise is proportional to the relative, not the absolute workload. ${ }^{19}$

\section{Thermoregulatory responses}

This study is believed to make a specific addition to the body of knowledge concerning the thermoregulation of paraplegics. The data collected here permit a comparison of the thermoregulatory abilities of TP and $\mathrm{AB}$ subjects performing arm ergometry exercise in both hot and cool conditions, which has not previously been made. Also, data on the thermoregulatory responses of paraplegics exercising in hot conditions has not been previously reported, and this has important implications for the safety of paraplegics performing prolonged exercise in hot and/or humid conditions.

There were few differences between the groups in their responses to the exercise in either hot or cool conditions. In the hot climate the TP recorded similar Tr, HR, [Hla] values and sweat rates to the $A B$ subjects, with the only significant difference recorded being a greater $\Delta \bar{T}$ sk $0-60 \mathrm{~min}$ in the TP. Therefore, in general, the TP exhibited a sound thermoregulatory ability in the face of a moderate exercise load performed for $60 \mathrm{~min}$ in a hot climate. However, one TP completed only $35 \mathrm{~min}$ of exercise in the heat, at which point his $\mathrm{HR}$ and $\mathrm{VO}_{2}$ were approximately $96 \%$ and $78 \%$ of maximum respectively. This subject was also asthmatic, which may have contributed to his distress during this exercise period. $\mathrm{He}$ had no difficulty in completing $60 \mathrm{~min}$ of exercise in the cool conditions.

The $\bar{T}$ sk of the TP in the hot climate rose steadily throughout the exercise period, whereas, in contrast, the $\bar{T}$ sk of the $\mathrm{AB}$ subjects decreased over the final $30 \mathrm{~min}$. A similar response was noted by Fitzgerald et al, ${ }^{5}$ during submaximal wheelchair ergometry for $90 \mathrm{~min}$ in cool conditions. As a result, the $\Delta \bar{T}$ sk value $(0-60 \mathrm{~min})$ recorded in the present study was significantly greater in the TP than the AB subjects. The individual Tsk responses of the lower limb in the TP may explain these divergent findings. Gass et $a l^{9}$ found that thigh and calf temperatures increased to a greater degree than arm and head temperatures in TP performing $80 \mathrm{~min}$ of continuous, moderate load exercise in cool conditions. Similar trends were found in the present study in the hot climate. The change $(0-60 \mathrm{~min})$ in sternum and arm temperatures were not significantly different between the two groups, but change in thigh and calf temperatures $\left(4.74 \pm 1.07^{\circ} \mathrm{C}\right.$ and $3.93 \pm 0.60{ }^{\circ} \mathrm{C}$ respectively) for the $\mathrm{TP}$ were significantly greater $(p<0.05)$ than recorded for the $\mathrm{AB}$ subjects $(2.63 \pm$ $0.36^{\circ} \mathrm{C}$ and $\left.1.50 \pm 0.32^{\circ} \mathrm{C}\right)$. 
These findings may be the result of blood pooling in the lower limbs in the TP due to poor muscle tone and venous return, which may in turn cause elevated thigh and calf temperatures. The spinal lesion level may be an important factor in this response. Gass et $a l^{9}$ found large increases in calf temperature during exercise in cool conditions with three subjects with lesions at T12. while, in contrast, two subjects with lesions at T10 showed small decreases. They suggested that the pathway for vasodilatory activity in the lower limb could be located at or below T10. The TP in the present study all had lesions at or below T12, thereby providing support for the previous findings of Gass et al. ${ }^{9}$ However, because none of the TP had lesion levels at or above T10, their suggested location of the vasodilatory pathway cannot be supported or rejected by the results of the present study. The difference in environmental temperature (i.e. cool versus hot) between these two studies may also have some bearing on the $\bar{T}$ sk responses, as a greater vasodilation stimulus would no doubt exist in hot, rather than cool, conditions. The wearing of tracksuit pants by all the subjects during the exercise sessions may also have affected the lower limb Tsk. The evaporation of sweat and convective heat exchange for the legs would have been restricted by the wearing of the pants, however this would apply to both groups of subjects, and as there were no significant differences in sweat rate between the TP and $\mathrm{AB}$ subjects, blood pooling in the lower limbs of the TP may be the most likely explanation for the differences noted in $\Delta$ T sk.

The $\Delta \mathrm{Tr}$ values recorded by the $\mathrm{TP}$ during exercise in the heat were almost exactly the same as for the $\mathrm{AB}$ subjects (TP: $0.65 \pm 0.12^{\circ} \mathrm{C}$ and $\left.\mathrm{AB}: 0.70 \pm 0.15^{\circ} \mathrm{C}\right)$ and their final $\mathrm{Tr}$ of approximately $37.7^{\circ} \mathrm{C}$ and sweat rate of almost $1000 \mathrm{~g} \mathrm{hr}^{-1}$ suggests that they were comfortably able to withstand the challenge to thermoregulation presented by the exercise load and the climate. While these results are a promising indication of the ability of TP to thermoregulate effectively during exercise in the heat, cardiovascular data (stroke volume and cardiac output) should be collected to investigate whether any changes in central blood volume may compromise the ability to continue exercise under these conditions.

Two other factors relevant for consideration when assessing these responses are the mode of exercise and the site of core temperature measurement. Arm ergometry involves a smaller exercising muscle mass than wheelchair propulsion, and it is possible that the arm crank exercise performed in this study did not produce enough metabolic heat to cause $\operatorname{Tr}$ to rise to higher and potentially more dangerous levels. Gass et $a l^{9}$ recorded similar rises to $\operatorname{Tr}$ (to those found here) in TP who performed $80 \mathrm{~min}$ of wheelchair exercise at $60-65 \% \dot{\mathrm{VO}}_{2} \max$ in cool conditions. Given the additional heat stress imposed by the hot climate in this study, it is likely that a greater magnitude of rise in core temperature would be experienced by paraplegics exercising in their wheelchairs. How effectively they could thermoregulate when performing this mode of exercise for a prolonged period in a hot climate is a topic worthy of investigation.

Gass et al ${ }^{9}$ have also shown that esophageal (Tes) temperature rose significantly faster than $\mathrm{Tr}$ in TP performing prolonged submaximal wheelchair propulsion in cool conditions. Such a difference has not been found in $\mathrm{AB}$ subjects. ${ }^{20}$ Poor venous return from the lower limbs in paraplegics could result in less warm blood passing via the rectal cavity and conceivably produce divergent $\mathrm{Tes}$ and $\mathrm{Tr}$ responses. The ability to redirect blood flow from the splanchnic area to more active areas during exercise would also be an important factor. This will depend on the lesion level, which will determine the amount of intact sympathetic innervation. Therefore, it is possible that the measurement of Tes values may have produced a different response to that exhibited in $\mathrm{Tr}$ values by the TP during the exercise sessions. Gass et $a l^{9}$ have also suggested that, apart from lesion level, factors such as fitness level, wheelchair design and seat position may alter venous return dynamics in subjects with similar lesion levels, and thereby contribute to Tes-Tr differences. The simultaneous measurement of Tes and $\mathrm{Tr}$ values in paraplegics exercising in hot conditions 
would provide further evidence of the thermoregulatory abilities of these subjects and may show differences not found here between TP and AB subjects.

In the cool climate, as might be expected, both the TP and $\mathrm{AB}$ subjects experienced little difficulty in completing the $60 \mathrm{~min}$ exercise period. Both groups were able to reach a plateau in $\mathrm{Tr}$ response after approximately $30 \mathrm{~min}$ of exercise and recorded decreases in $\bar{T}$ sk across the exercise period, suggesting that, under these exercise and environmental conditions, the TP were capable of effective evaporative cooling. Gass and colleagues ${ }^{8.9}$ have previously shown that paraplegic men can perform prolonged submaximal exercise in cool conditions without experiencing marked thermoregulatory strain.

In conclusion, for the exercise and climatic conditions used in this study, it was found that TP can successfully regulate their body temperatures during prolonged submaximal exercise in hot and cool climates at a level comparable to that of $\mathrm{AB}$ subjects performing identical exercise. Whether this is also the case during wheelchair propulsion at higher intensities of exercise should be investigated. Future research might also investigate the Tsk responses of paraplegics exercising in hot conditions more closely, as lower limb surface temperatures may be increased considerably due to venous pooling.

\section{Acknowledgements}

The enthusiastic efforts of subjects during the study is gratefully acknowledged, as is the cooperation and advice given to us by the staff at the Royal Perth (Rehabilitation) Hospital spinal injuries unit.

\section{References}

1 Costill DL, Thomason H, Roberts E (1973) Fractional utilization of the aerobic capacity during distance running. Med Sci Sports 5: 248-252.

2 Seckendorf R, Randall WC (1961) Thermal reflex sweating in normal and paraplegic man. J Appl Physiol 16: 796-800.

3 Guyton AC (1981) Textbook of Medical Physiology. WB Saunders Co.

4 Guttman WL, Silver J, Wyndham CH (1958) Thermoregulation in spinal man. J Physiol 142: 406-419.

5 Fitzgerald PI, Sedlock DA, Knowlton RG (1990) Circulatory and thermal adjustments to prolonged exercise in paraplegic women Med Sci Sports \& Ex 22: 629-635.

6 Gass GC, Camp EM, Davis HA, Eager D. Grout L (1981) The effects of prolonged exercise on spinally injured subjects. Med Sci Sports \& Ex 13: 277-283.

7 Gass GC, Camp EM (1984) The maximum physiological response during incremental wheelchair and arm cranking exercise in male paraplegics. Med Sci Sports \& Ex 16: 355-359.

8 Gass GC, Camp EM (1987) Effects of prolonged exercise in highly trained traumatic paraplegic men. J Appl Physiol 63: 1846-1852.

9 Gass GC, Camp EM, Nadel ER, Gwinn TH, Engel P (1988) Rectal vs esophageal temperatures in paraplegic men during prolonged exercise J Appl Physiol 66: 2265-2271.

10 Cohen JS, Gisolfi CV (1982) Effects of interval training on work-heat tolerance of young women. Med Sci Sports Exerc 14: 46-52.

11 Fortney SM, Senay LC (1979) Effect of training and heat acclimation on exercise responses of sedentary females. J Appl Physiol 47: 978-984.

12 Gisolfi CV (1973) Work-heat tolerance derived from interval training. J Appl Physiol 35: 349-354.

13 Astrand P-O, Rodahl K (1977) Textbook of Work Physiology. 2nd edition. McGraw Hill.

14 Nag PK (1982) Influence of posture and speed of arm and leg work on physiological responses. J Sports Med 22: 426

15 Williams J, Cottrell P, Powers SK, McKnight T (1983) Arm ergometry: a review of published protocols and the introduction of a new height adjusted protocol. J Sports Med 23: 107.

16 Ramanathan NL (1964) A new weighting system for mean surface temperature of the human body. J Appl Physiol 19: 531-533.

17 Davis GM, Shephard RJ (1988) Cardiorespiratory fitness in highly active versus inactive paraplegics. Med Sci Sports Exerc 20: 463-468.

18 Van Loan MD, McCluer S, Loftin JM. Boileau RA (1987) Comparison of physiological responses to maximal arm exercise among able-bodicd. paraplegics and quadriplegics. Paraplegia 25: 397-405.

19 Saltin B, Hermansen L (1966) Esophageal, rectal and muscle temperature during exercise. J Appl Physiol 21: 1757-1762. 
20 Sawka MN, Pimental NA. Pandolf KB (1984) Thermoregulatory responses to upper body exercise. Eur $J$ Appl Physiol 521: 230-234.

21 Telford RD, Tumulty D, Damm G (1984) Skinfold measurements in well performed Australian athletes. Sports Sci Med Q 1: 13-16. 